\section{Eliminating Use of the Linear No-Threshold Assumption in Medical Imaging}

TO THE EDITOR: The lead article, by Siegel et al. (1), in the January 2017 issue of The Journal of Nuclear Medicine is brilliant, timely, and scientifically superb. Unfortunately, the Invited Perspective by Weber and Zanzonico (2) that follows it is scientifically poor and inconsistent. The authors strive to hang on to the long-outdated ideas espoused by government bureaucrats by implying that we just do not know the truth yet, and they ignore a huge mass of valid scientific literature in doing so.

Calling the linear no-threshold (LNT) model controversial is the first problem. A solid body of science is against it, and those who treat it as a religion —or whose jobs, contracts, grants, or consulting positions depend on acceptance of the LNT model-are in favor of it. That does not make it controversial. Weber and Zanzonico quote a few studies to support the LNT model that have been discredited because of biased statistics, insufficient data, wrong data, and faulty experimental design. They ignore a large body of credible data covered in part in the paper by Siegel et al.

Weber and Zanzonico admit that there is radiation repair. Absence of radiation repair is an essential assumption of the LNT. Right there they are inconsistent. One cannot admit to radiation repair and still be an LNT advocate without being scientifically inconsistent.

Weber and Zanzonico claim, "No prospective epidemiologic studies with appropriate nonirradiated controls have definitively demonstrated either the adverse effects or the hormetic effects of radiation doses under $100 \mathrm{mSv}$ (10 rem) in humans, and current estimates of the risks of low-dose radiation indicate that very largescale epidemiologic studies with long-term follow-up would be needed to actually quantify any such risk or benefit; such studies may be logistically and financially prohibitive." I disagree and mention two examples. In Canadian sanatoriums from 1930 to 1952, 31,710 female patients with tuberculosis were subjected to multiple fluoroscopies to monitor their disease status $(3,4)$. Of these patients, $26.4 \%$ received radiation doses of $10 \mathrm{cGy}$ (10 rads) or more to the affected side, and therefore most received lower doses. The relative risk of eventual breast cancer was studied in all these patients. Patients who received a total absorbed radiation dose in the range of 530 cGy (5-30 rads) had a breast cancer incidence up to one third less than the baseline incidence. Only at absorbed radiation doses above 50 cGy (50 rads) did the cancer incidence begin to increase above baseline. In these patients, the unirradiated breast was the control.

After World War II, patients with hyperthyroidism began to be treated with ${ }^{131} \mathrm{I}-\mathrm{NaI}$ instead of surgery. There was concern about late effects from the radiation. The Cooperative Thyrotoxicosis Therapy Follow-Up Study of over 36,000 treated hyperthyroid patients looked at eventual leukemia rates in these patients, as leukemia is considered among the most radiosensitive of cancers and occurs faster than other radiogenic cancers. The total-body radiation doses to the patients treated with ${ }^{131}$ I were $130-140 \mathrm{mSv}(13-$ 14 rem). The age-adjusted leukemia incidence rate was 11/100,000 patient-years in patients treated with ${ }^{131} \mathrm{I}$ and $14 / 100,000$ patient-years

COPYRIGHT @ 2017 by the Society of Nuclear Medicine and Molecular Imaging. in patients treated with surgical removal of the thyroid gland. Although the authors concluded that there was no increased incidence of leukemia at this low whole-body radiation dose (5), the $22 \%$ decrease in the ${ }^{131}$ I-treated patients suggests a possible hormetic effect. The surgery-treated patients were the controls, the number of patients followed was large, and all had hyperthyroidism.

The poor scientific quality of the Weber and Zanzonico commentary is perhaps the most important feature of their contribution. If this is the best the agnostics can do, it is certainly a plus for finally removing the LNT model from radiation protection "science." The earth is not flat, there is no ether, disease is not caused by miasmas, and the LNT model is wrong because of our knowledge of repair and carcinogenesis mechanisms.

\section{REFERENCES}

1. Siegel JA, Pennington CW, Sacks B. Subjecting radiologic imaging to the linear nothreshold hypothesis: a non sequitur of non-trivial proportion. J Nucl Med. 2017; 58:1-6.

2. Weber W, Zanzonico P. The controversial linear no-threshold model. J Nucl Med. 2017;58:7-8.

3. Cuttler JM, Pollycove M. Can cancer be treated with low doses of radiation? J Am Phys Surg. 2003;8:108-111.

4. Miller AB, Howe GR, Sherman GJ, et al. Mortality from breast cancer after irradiation during fluoroscopic examinations in patients being treated for tuberculosis. N Engl J Med. 1989;321:1285-1289.

5. Thompkins E. Late effects of radioiodine therapy. In: Cloutier RJ, Edwards CL, Snyder WS, eds. Medical Radionuclides: Radiation Dose and Effects-Proceedings of a Symposium Held at the Oak Ridge Associated Universities, December 8-11, 1969. Germantown, MD: U.S. Atomic Energy Commission, Division of Technical Information; 1970:431-440.

Carol S. Marcus
David Geffen School of Medicine at UCLA
1877 Comstock Ave.
Los Angeles, CA 90025-5014
E-mail: csmarcus@ ucla.edu

Published online Feb. 16, 2017.

DOI: 10.2967/jnumed.117.189860

TO THE EDITOR: We thank The Journal of Nuclear Medicine for asking us to write a Special Contribution article advocating rejection of the linear no-threshold (LNT) assumption in medical imaging (1). We note that all valid evidence favors either no risk or health benefit (hormesis) in the low-dose range (at least for the vast majority) and invalidates the LNT model, which wrongly asserts harm at all dose ranges.

In contrast, immediately after our article, an Invited Perspective article by Drs. Weber and Zanzonico (2) proposes an agnostic position, sometimes agreeing with us and at other times mentioning, only to dismiss, certain putatively LNT-supporting studies-most prominently, the International Agency for Research on Cancer studies using data from the International Nuclear Workers Study, which we have shown contains numerous errors (3), and an analysis in 2000 of the Life Span Study atomic bomb survivor data that we, and others, have shown to be erroneous, except for the reported possible existence of a threshold 
$(1,4,5)$. In doing so, Weber and Zanzonico one-sidedly focus on risk in the low-dose region as the default assumption, neglecting benefit.

Most tellingly, they imply that prospective studies are the only valid basis on which to decide, but they simultaneously say that such studies may be "logistically and financially prohibitive," not to mention possibly unethical. Thus, as the basis of regulatory policy and medical practice, they ensconce LNT in a position impervious to further (obtainable) evidence and implicitly reject the mounting nonprospective evidence against it.

Indeed, many, if not most, medical conclusions and practices have been arrived at without prospective studies, which would often be unethical. For example, in the 19th century a stunning insight by Dr. John Snow, that cholera was caused by sewage in the water supply, led to the purification of the water supply with salutary results. No prospective trial was ever performed, nor could it be performed ethically. Without the practical or ethical possibility of prospective studies, Bayesian estimates of probability have successfully been used to reach conclusions that have held as the best medical practices.

Moreover, many experimental and epidemiologic studies show benefit, rather than risk, from low-dose exposures $(1,3)$. Furthermore, no ill health effects associated with natural background radiation levels have been documented anywhere in the world $(5,6)$. The assertion of BEIR (Biological Effects of Ionizing Radiation) VII that such ecologic metastudies are meaningless puts the burden on the committee to identify confounders or other factors that can account for these consistent findings, rather than simply dismissing them a priori.

It should be noted that, whereas all medical procedures require justification and optimization, the International Commission on Radiological Protection recommendation that this apply to lowering radiation exposure (to as low as reasonably achievable) is scientifically unjustified and medically counteroptimal.

As we reported, in a recent study of young adults undergoing body $\mathrm{CT}$, the observed risk of death was found to be more than an order of magnitude greater than the hypothetical LNT-predicted risk of dying from radiation-induced cancer. Underlying morbidity, rather than CTinduced cancer, is the dominant factor driving adverse outcomes. A controlled randomized trial comparing outcomes of patients who did and did not undergo CT would be the definitive prospective study to measure the benefits (versus risks) incurred by imaging. However, withholding CT for such a trial would be unethical.

Weber and Zanzonico conclude with the hopeless statement that "the debate over LNT will not be resolved anytime soon." With agnosticism being forcefully injected into the evidential imbalance that characterizes the LNT-versus-hormesis debate, it will never be resolved. The all too common reticence to accept the available and mounting evidence that is decidedly in favor of hormesis and soundly against LNT, and the displacement of the burden of proof from the evidence-absent LNT to the evidence-rich hormesis, are unscientific, as well as assuredly unethical.

\section{REFERENCES}

1. Siegel JA, Pennington CW, Sacks B. Subjecting radiological imaging to the linear no-threshold hypothesis: a non sequitur of non-trivial proportion. J Nucl Med. 2017;58:1-6.

2. Weber W, Zanzonico P. The controversial linear no-threshold model. J Nucl Med. 2017;58:7-8.

3. Sacks B, Meyerson G, Siegel JA. Epidemiology without biology: false paradigms, unfounded assumptions, and specious statistics in radiation science (with commentaries by Inge Schmitz-Feuerhake and Christopher Busby and a reply by the authors). Biol Theory. 2016;11:69-101.
4. Ozasa K, Shimizu Y, Suyama A, et al. Studies of the mortality of atomic bomb survivors, report 14, 1950-2003: an overview of cancer and noncancer diseases. Radiat Res. 2012;177:229-243.

5. Siegel JA, Welsh JS. Does imaging technology cause cancer? Debunking the linear no-threshold model of radiation carcinogenesis. Technol Cancer Res Treat. 2016;15:249-256.

6. Dobrzyński L, Fornalski KW, Feinendegen LE. Cancer mortality among people living in areas with various levels of natural background radiation. Dose Response. 2015; $13: 1559325815592391$.

\author{
Jeffry A. Siegel* \\ Bill Sacks \\ *Nuclear Physics Enterprises \\ 4 Wedgewood Dr. \\ Marlton, NJ 08053 \\ E-mail: nukephysics@comcast.net
}

Published online Feb. 16, 2017.

DOI: 10.2967/jnumed.117.189928

REPLY: Despite their critical nature, we very much appreciate the comments by Dr. Marcus and Drs. Siegel and Sacks on our Invited Perspective (1). We further appreciate the unmistakable passion they bring to the issue of dose-response relationships in the context of low-level radiation. Importantly, our commentary was not intended as either an endorsement or a refutation of the linear no-threshold (LNT) dose-response model or of any alternative model. Rather, our intent was to provide some background on this issue for the readership of The Journal of Nuclear Medicine. The publication by Siegel et al. (2) had already made a compelling case for the fallacy of the LNT model, and it would have been inappropriate, we feel, to simply ignore the large body of scientific literature that supports or at least does not refute the LNT model-even if this model is ultimately discredited. Such an effort inevitably results in the citation of publications that bolster as well as undermine different scientific positions. Our commentary concluded as follows: “... .even if one concedes the validity of the LNT model, it cannot be applied reliably to individuals but only to large populations... and application with certitude of population-derived risk factors to individual patients or even defined patient populations is simply not justified." Although ignored in the letters from Dr. Marcus and Drs. Siegel and Sacks, and despite our presumed agnosticism, the foregoing conclusion amounts to a tangible refutation of the LNT model in a very important context, that of clinical practice.

\section{REFERENCE}

1. Weber W, Zanzonico P. The controversial linear no-threshold model. J Nucl Med. 2017;58:7-8.

2. Siegel JA, Pennington CW, Sacks B. Subjecting radiologic imaging to the linear nothreshold hypothesis: a non sequitur of non-trivial proportion. J Nucl Med. 2017; 58:1-6.

Wolfgang Andreas Weber*
Pat Zanzonico
*Memorial Sloan Kettering Cancer Center
1275 York Ave., Box 77
New York, NY 10065
E-mail: weberw@mskcc.org

Published online Feb. 23, 2017.

DOI: 10.2967/jnumed.117.190173 